\title{
Relato de experiência: Uma narrativa científica na pós-modernidade
}

\section{Experience report: A scientific narrative in the post-modernity}

\section{Relato de experiencia: Una narrativa científica en la posmodernidad}

\section{Mônica Ramos Daltro*}

Escola Bahiana de Medicina e Saúde Pública - Bahiana, Salvador, Bahia, Brasil

\author{
Anna Amélia de Faria** \\ Escola Bahiana de Medicina e Saúde Pública - Bahiana, Salvador, Bahia, Brasil
}

\begin{abstract}
RESUMO
A construção do conhecimento científico organiza-se numa multiplicidade, permanentemente desafiada a elaborar modos de leituras da realidade. Esse estudo apresenta o Relato de Experiência (RE) como produto científico próprio às ciências humanas e à pós-modernidade. Análise documental realizada entre 12/2017-01/2018, pesquisou periódicos da área da psicologia, classificados no quadriênio 2013-2016, na Plataforma Sucupira. Analisados 170 periódicos, identificou-se que apenas cinco aceitam o RE como um documento científico, esses de origem brasileira e vinculadas aos mais importantes programas de pós-graduação na psicologia brasileira e situados nas regiões Sudeste e Centro-Oeste. O Resultado reafirma a limitada força política do RE e a potência da perspectiva empirista cartesiana nos domínios da pesquisa em psicologia. Neste artigo, discute-se a importância do RE como narrativa que legitima a experiência enquanto fenômeno científico, e propõe-se seis passos de referência para sua construção.

Palavras-chave: relato de experiência, pesquisa, ciências humanas, pósmodernidade, pesquisa qualitativa.
\end{abstract}

\begin{abstract}
The construction of scientific knowledge is organized in a multiplicity, permanently challenged to elaborate ways of reading reality. This study presents the Report of Experience (RE) as a scientific product specific to human sciences and postmodernity. The study is a documentary analysis carried out between 12/2017-01/2018, that has researched periodicals of the psychology area, classified in the quadrennium 2013-2016 in the Platform Sucupira. After analyzing 170 journals, it was identified that only five accepted the ER as a scientific document, those of Brazilian origin and linked to the most important post-graduate programs in Brazilian psychology and located in the Southeast and Center-West regions. This result reaffirms the limited political force of the RE and the power of the cartesian empiricist perspective in the fields of psychology research. We discuss the importance
\end{abstract}


of RE as a narrative that legitimizes experience as a scientific phenomenon and proposes six reference steps for its construction.

Keywords: experience report, research, human science, postmodernity, qualitative research.

\begin{abstract}
RESUMEN
La construcción del conocimiento científico se organiza en una multiplicidad, con el desafío permanente de elaborar formas de leer la realidad. Este estudio presenta el Informe de experiencia (ER) como un producto científico específico para las ciencias humanas y la posmodernidad. El estudio es un análisis documental realizado entre el 12/2017-01/2018, publicaciones periódicas investigadas del área de psicología, clasificadas en el cuadrienio 2013-2016 en la Plataforma Sucupira. Después de analizar 170 revistas, se identificó que solo cinco aceptaron la ER como documento científico, las de origen brasileño y vinculadas a los programas de posgrado más importantes de la psicología brasileña y ubicadas en las regiones sudeste y centro-oeste. Este resultado reafirma la fuerza política limitada de la ER y el poder de la perspectiva empesista cartesiana en los campos de la investigación en psicología. Discutimos la importancia de la ER como una narrativa que legitima la experiencia como un fenómeno científico y propone seis pasos de referencia para su construcción.
\end{abstract}

Palabras clave: informe de experiencia, investigación, ciencias humanas, postmodernidad, investigación cualitativa.

A construção do conhecimento científico organiza-se numa multiplicidade, permanentemente desafiada a elaborar modos de leituras sobre a realidade, envolvendo ideologias, metodologias, interações dialógicas entre sujeitos, contextos e pesquisadores, além de concepções sociopolíticas e históricas, afirma Pedro Demo (2011). Partindo desse ponto de vista, esse artigo pretende destacar a importância do Relato de Experiência - RE, como mais uma possibilidade de criação de narrativa científica, especialmente no campo das pesquisas capazes de englobar processos e produções subjetivas, como é o caso da psicologia e das ciências humanas aplicadas, entre outras.

No âmbito da pesquisa empírica, de ideal positivista, os desenhos de pesquisa empenham-se em produzir conhecimentos que possibilitem a construção de generalidades; perspectiva associada a procedimentos que envolvem repetições, padronizações, construções teóricas, que contemplem categorias nas quais todos ou a maioria de indivíduos, ou processos, possam estar compreendidos enquanto fenômenos universais, como indica Gonzáles-Rey (2002). Perspectivas dessa natureza tendem a minimizar a importância do RE como produção científica que, entretanto, performatiza através da linguagem a experiência do um, não enquanto centralidade estável, mas na condição de ponto de abertura e análise crítica.

A crítica a essa hegemonia de tradição científica fratura a suposta centralidade do sujeito, limitando a potência racionalista, herança 
encetada pelos românticos, em que afirmavam um conhecimento não mais exclusivo em métodos universalizantes, mas provenientes das percepções que descentralizavam o sujeito da razão. O livro, escrito no século XIX, 1886, O Médico e o Monstro, de Robert Louis Stevenson (2015), apresenta uma problemática voltada ao ilimitado desejo de conhecer, atando ao ser cognoscente suas tendências inconscientes mais exigentes. O livro contribui com a discussão sobre elementos éticos e morais, porque demonstra a insuficiência do meio cultural para refrear as paixões humanas e aponta a singularidade como parte interessada em tudo aquilo que toca. Há uma luta entre o bem e a moral, coletivo e singular. Advém daí uma lição para os tempos pós-modernos, ao desdizer as linhas gerais da modernidade, naquilo que suportavam e aspiravam no direcionamento de concepções amplas sintéticas.

Entende-se por pós-modernidade um rebaixamento da herança moderna à pretensão de narrativas universalizantes. De acordo com Lyotard (1987), esse conceito foi concebido pela arquitetura, e ganhou importância para referenciar tensões e dilemas no campo da política, arte e expressões do pensamento. Vê-se, na particularidade da literatura, uma provocação às pretensões edificantes historicamente deflagradas e majoritariamente encenadas por figuras masculinas, autopromovidas a universais - propostas no Ocidente. Homens que, da Antiguidade à Modernidade, construíram as grandes perspectivas dos discursos sobre a ciência moderna e visão de mundo.

A Modernidade buscou, na crença da razão e na valorização da ciência, o formato para sua Enciclopédia. O Iluminismo intentou consolidar o afastamento da crença na Igreja e firmou um pacto com a ciência, colocada como substituta de Deus para se figurar com esplendor na abóboda celeste. De maneira prática, foram desenvolvidos dispositivos narrativos, altamente valorizados e prestigiados para auferir mais vigor a esse modo de conhecimento. Ironicamente, um dos inúmeros efeitos ocasionados na solidez cientificista foi o banimento do lugar do sujeito enquanto operador ativo do conhecimento. Buscou-se ambiguamente assegurá-lo, apagando-o, posicionando-o de duas maneiras expostas em um modo de narrar. Primeiro, na insidiosa busca da neutralidade; segundo, na materialização da neutralidade, desdobrada nas fraseologias em voz passiva.

As pesquisas no âmbito da psicologia e das ciências sociais aplicadas, entre outras, que têm o valor heurístico como princípio, assumem a priori estudos capazes de compreender o desenvolvimento das subjetividades como irredutíveis a fórmulas universais. Com isso, para conhecer, importa o gesto inventivo afirmando o um, não mais enquanto operador neutro, mas atuante e atravessado de forma relacional, que age e interage, abrindo-se para se afirmar como 
particularidade, participante e ativa. Daí vir a aptidão para deflagrar zonas de interesses comuns e generalizantes, vistas nas etapas do conhecimento generalizado. O narrado pode ser apreendido e, a partir disso, utilizado como argumento para outra volta linguageira, que encaminhará uma nova possibilidade de relação. Então, um campo imantado nas narrativas que o constrói torna-se campo, devido às relações dialéticas nele deflagradas. Para González-Rey (2002), nesta perspectiva, as generalizações deixam de ser um ato descritivo de constatação de verdades, para assumirem um caráter construtivo. Conforme o autor,

“ (...) a generalização é um processo teórico que permite integrar em um mesmo espaço de significações elementos que antes não tinham relações entre si em termos de conhecimento. Seria um erro de caráter empirista compreender a generalização como um produto final ou produção universal, pois só é um momento do processo de conhecimento que se expressa na temporalidade e historicidade que marca 0 desenvolvimento daquele." (González-Rey, 2002, p. 164)

A generalização está assim concebida enquanto processo definido pelas relações entre categorias no contexto teórico, histórico e temporal em que se insere, e resulta na emergência de outras versões sobre o fenômeno em foco. Com esta referência, o presente estudo destaca o potencial de generalização do Relato de Experiência (RE). O RE situa o saber resultante de um processo; melhor dizendo, pode-se considerá-lo em um entrecruzamento de processos, dos coletivizados aos mais singulares.

No tocante aos processos singulares, é importante salientar que o RE poderá ser conhecido como um resultado après-coup, no sentido psicanalítico, é, em um só depois, visto enquanto efeito de algo que o impactou (Roudinesco, 1998. p. 32), e utilizamos o termo de modo lato sensu. Pressupõe-se no RE um trabalho de concatenação e memória, a elaboração de um acontecido que como vê seu relator, invocando suas competências reflexivas e associativas, bem como suas crenças e posições de sujeito no mundo. Então, o trabalho narrativo da singularidade no RE é sempre e invariavelmente um trabalho de linguagem. É importante notar que, através da linguagem, que afeta a singularidade diferentemente, de modo extra e intrasingular - extra porque o código de linguagem precede quem o utiliza, e intra porque será, por meio de sucessivas operações, realizadas por cada um, a necessária condição e medida para poderse falar "eu" - o eu, posto de formas distintas, advém como um relevante dispositivo de formação da experiência. Entretanto, o eu é a síntese impossível e intranquila de inúmeros atravessamentos. 
$\mathrm{Na}$ constelação de fatores englobados no RE, todos cernidos na linguagem, a experiência ocorre em simultaneidade a ideias e acontecimentos, concepção consoante aos estudos de Macedo (2016), quando se refere à pesquisa como "acontecimento". Para ele, a experiência é compreendida a partir de duas perspectivas: primeiro, como inseparável da subjetividade; e segundo, como promotora do que chama de "memória incorporada" em um corpo que simultaneamente cria e é habitado pela experiência.

Demarca-se assim a experiência como objeto de análise do RE, uma fonte inesgotável de sentidos e possibilidades passíveis de análises. Com isso, há inúmeras possibilidades narrato/descritivas advindas dos encontros irredutíveis apresentados nos RE. Algo resta e é passível de ser recontado e visto de outra maneira, pois o RE é o resultado de um acontecimento que passou pelo corpo de seu relator em um determinado momento. O tempo do relato marca sua dicção, está trançado às condições afetivas, ideologias, e a aspectos intersubjetivos com as suas significações histórico- sociais. Dessa forma, rompe e não coaduna com um ponto de vista de verdades imutáveis, únicas ou "descorporificadas".

A propósito da posição a ser ocupada pelo pesquisador, tomamos como referência o texto do poeta português Fernando Pessoa (2011), quando declara a respeito da experiência: "aquilo que em mim sente está pensando". Ao ser sensibilizado por elementos perceptivos, o sujeito/pesquisador aciona compreensões que representam e desenvolvem novas significações inscritas na realidade de seu corpo, deslocando-o para uma posição de autor e simultaneamente sujeito da experiência. Trata-se de reconhecer um paralelismo psicofísico, referindo-nos à compreensão deleuziana sobre o entendimento do filósofo moderno Baruch Espinosa, que combinava as repercussões entre o corpo e a mente sem ligação de causalidade, e sem reconhecer iminência de um sobre o outro (Deleuze, 2002. p. 24). Portanto, a experiência de se fazer pesquisador de um RE rompe com os pressupostos cartesianos que instam ser a razão a detentora das decisões/produções humanas. Devido à simultaneidade pensar/sentir, o pensar surge enquanto combinação, e não o determinante que orienta o curso.

Entretanto, não somente a poesia desdiz a dominância do pensamento sobre o corpo. Anterior a Fernando Pessoa, Spinoza (2008), no século XVII, criticou René Descartes a respeito das dimensões do pensar e sentir. Espinosa, em sua filosofia, organizada na Ética, apresentava o entrelaçamento dos processos das afecções e das ideias, o paralelismo corpo e mente fora demonstrado de modo a evidenciar seu entendimento. Se algo afetasse o corpo, o mesmo impulso iria causar na mente uma ação; por sua vez, a ação da mente produzia ideias advindas das afecções do corpo. Ele escreveu na proposição XXVI, na segunda parte de seu livro, A natureza e a 
origem da mente: "A mente humana não percebe nenhum corpo exterior como existente em ato senão por meio das ideias das afecções de seu próprio corpo". (Spinoza, 2008, p. 119). Combina-se à essa compreensão a vivência, expressada nos versos de Pessoa (2011), que apresenta um eu poético que ouve o canto da pobre ceifeira:

Ah, poder ser tu, sendo eu!

Ter a tua alegre inconsciência, E a consciência disso, ó céu!

No mesmo poema, Pessoa mostra múltiplos desdobramentos: ele ouve, sente e pensa. E, enquanto pensa, ele se meta representa. No poema, o eu poético imagina-se ela, sabendo ser ele; com isso, no tempo exíguo em que algo sucede, certos movimentos perceptivos e subjetivos ocorrem e, mesmo que deixemos para outro momento questões relacionadas à percepção e intelectuação, propomos pensar - RE como uma narrativa que, tal qual pressupõe o poeta, posiciona singularidades envolvidas em um tempo de pensar, sentir e recordar. Entretanto, o processo de escrita realiza-se no après coup, um tempo necessário de decantação e elaboração. Com isso, a conclusão não se coloca totalizante, pois ela guarda sempre um vínculo com 0 momento do acontecimento relatado na pesquisa. Em síntese e, analogamente, o RE será criado enquanto efeito combinado ao tempo de existir do narrador, e fundamentado, posteriormente, a partir de outros saberes teóricos.

Trata-se de pensar o RE em perspectiva epistemológica, expandida a partir das singularidades, sendo, consequentemente, um importante produto científico na contemporaneidade. Isso porque refere-se a uma construção teórico-prática que se propõe ao refinamento de saberes sobre a experiência em si, a partir do olhar do sujeitopesquisador em um determinado contexto cultural e histórico. Sem a pretensão de se constituir como uma obra-fechada ou conjuradora de verdades, desdobra-se na busca de saberes inovadores.

Abre-se então a discussão sobre a validade desse tipo de conhecimento, produzido no contexto epistemológico. Para GonzálezRey (2002), o termo validade não pode ser atribuído a estudos de natureza qualitativa, pois estes não envolvem instrumentos calibrados, manifestações empíricas de objetos ou relações lineares entre construção teórica e definição empírica. O referido autor prefere trabalhar com o conceito de legitimidade em lugar de validade. Para ele, a legitimidade de um conhecimento está dada a partir da possibilidade de se avançar na construção teórica do que se estuda, assimilando novas construções de sentido sem perder a integridade. O valor do conhecimento será julgado pela sua capacidade de construção do estudado, integrando, aspectos qualitativos e críticos 
das construções teóricas que tenham significado em relação à realidade estudada.

O RE é uma modalidade de cultivo de conhecimento no território da pesquisa qualitativa, concebida na reinscrição e na elaboração ativada através de trabalhos da memória, em que o sujeito cognoscente implicado foi afetado e construiu seus direcionamentos de pesquisa ao longo de diferentes tempos. Isso posto, conjugará seu acervo associativo agindo processualmente, tanto em concomitância com o evento, como trazendo o produto processado pelas elaborações e em suas concatenações, e, finalmente, apresentará algumas das suas compreensões a respeito do vivido.

A concretização narrativa desses impactos e direcionamentos demonstram um acordo e um termo em que o pesquisador construirá suas escolhas e, necessariamente, decidirá interromper o fluxo de possibilidades dos inesgotáveis períodos reflexivos, para afirmar e processar uma sistematização sobre a experiência vivida. Nessa medida, sua construção documental deve apresentar a natureza pluridimensional do que está sendo estudado. Espera-se, com isso, novos conceitos teóricos com capacidade de provocar a emergência de problematizações de conhecimento científico, organizados pela experiência/versão do autor.

$\mathrm{Na}$ perspectiva aqui colocada, o RE ultrapassa essa identidade descritiva, embora a contemple. Concebido como um estudo de natureza qualitativa, o RE caracteriza-se por uma multiplicidade de opções teóricas e metodológicas; e valoriza a explicitação descritiva, interpretativa e compreensiva de fenômenos, circunscrita num tempo histórico. Seus objetivos circulam em torno de subjetividades provisoriamente objetivadas, consonante com os estudos de Minayo (2004), que coloca que o processo descritivo e interpretativo está, definitivamente, atravessado pelo olhar/leitura do pesquisador, ao tempo que 0 ato de compreender também está relacionado ao universo existencial, campo que não admite a produção de verdades unívocas. Pelo contrário, compreende a produção do conhecimento como processo, sempre polissêmico, que abrange a cultura.

O RE é então arquitetado, de forma geral, como ultrapassagem, na medida em que essas atividades de elaboração do pesquisador não permitem a apresentação da experiência em termos binários: realidade/fantasia; endógeno/exógeno, determinismo/hermenêutica, passado/futuro. O conhecimento é construído contemplando a complexidade e a dimensão multifatorial, na qual certas distinções não se sustentariam de forma tão clara. Ao se distanciar de dualismos, típicos de uma lógica positivista, surge a plena atividade e a orquestração de compreensões e concatenações associativas, a serem teoricamente elaboradas e buriladas como as palavras na poesia. 
Afinal, desde o início do século XX, Einstein revolucionou a concepção científica do tempo com a Teoria da Relatividade Geral, construindo a ideia de espaço-tempo, o tecido que ordena o universo composto de matéria/energia, e que também não comporta uma distinção clara entre passado, presente e futuro, os quais seriam ilusões subjetivas.

Numa arquitetura que busca alcançar sujeitos, acontecimentos e temporalidades, o Relato imbrica outros processos e saberes, ligados a modalidades de construções científicas mais aptas a reconhecer a importância da utilização das competências narrativas. Na medida de desconfianças, tensões políticas e consequente rebaixamento de discursos pretensiosos universalizantes - deflagrados por movimentos diaspóricos histórico/políticos - a potência narrativa chega como um modo de contar e de legitimar discursos sobre a singularidades como narrativas científicas competentes. Como já foi dito, o Relato demonstra a história, histórias e a importância de haver vozes plurais para contá-la(s). Lyotard (1987) indica ser a narrativa a forma de tratar a história.

As construções científicas possuem competências ligadas ao uso de diferentes perspectivas teórico-metodológicas. De forma mais instrumental, e para anunciar o resultado de pesquisas, se expressam através da escolha vocabular, e demonstram, a partir do rol de pesquisas utilizadas, o pertencimento a diferenciados graus de prestígio das coletividades, pois as teorias e metodologias aceitas no meio acadêmico/científico dialogam com pressupostos políticos, econômicos e ideológicos do campos epistemológicos aos quais se alinham e pertencem.

Construído para responder como produto científico, o RE coloca ao pesquisador o desafio de articular teoricamente conhecimentos que marcam seu pertencimento coletivo, ao mesmo tempo em que ativam suas competências de tradução, percepção e interpretação. No processo que inclui as ativações singulares, consideramos para esse trajeto a noção de inconsciente, visto a partir da segunda tópica freudiana. Sigmund Freud (1933) refratou a subjetividade do indivíduo, diminuiu a dominância da sua consciência, desmontou a ineficácia da pretensão do assenhoramento decisório, e apontou o inconsciente como lugar movedor de sentidos. Significa que o inconsciente comporta uma marca, uma inscrição que vem de fora. As experiências vividas pelo sujeito combinam-se em torno e em razão dessa inscrição.

Destarte, há um não saber, algo que escapa no que é mais íntimo ao sujeito. Não há, portanto, um controle pleno por parte da instância consciente, pois o íntimo vem de fora, vem enquanto inscrição de sua troca com o ambiente. Em certa medida, o Eu é sempre um outro, não como síntese, mas enquanto solução traidora, invertida, complexa, que ativa na mensagem recebida do mundo uma dicção não controlada, mas que lhe é própria. 
Essa perspectiva, validada no rol dos conhecimentos vinculados às ciências humanas e ciências sociais aplicadas, afirma o RE como uma construção científica que circunscreve o posicionamento do pesquisador político, epistemológico e temporal, mas envolve também seu mundo interno exposto e em troca com o seu meio. Do seu lugar de fala e, na fala narrada, demonstra também seus encontros com as unidades que the são anteriores, como, por exemplo, a economia e a geopolítica que o circundam. Essas unidades serão tomadas enquanto elemento crítico, essa troca aciona sua forma de narrar seu ethos com as suas respectivas possibilidades e responsabilidades analíticas. Dessa maneira, nunca o RE poderá se estabelecer como universal, replicável ou passível de validação pois, naquilo que localiza seu território discursivo, ele mesmo estará alinhado às produções que compreendem o conhecimento visto nas territorializações que dão-se a ver.

Utilizar O RE como metodologia de construção de conhecimento científico, de forma descentralizada, significa abdicar da pretensão moderna do discurso unificado e total. Entretanto significa também compreender que o discurso está afetado por fatores exteriores, conscientes e inconscientes daquele que profere a palavra narrativa e tem potência de contribuição social. O discurso, como ensina Foucault (2012), é uma representação culturalmente construída pela realidade. Nessa perspectiva, o RE, como uma construção discursiva, demanda a inclusão crítica dos elementos históricos ali circulantes, e os efeitos possíveis de serem apreendidos pela lente do autor.

No RE, a singularidade assume a afirmação de criação cognoscente. O sujeito utiliza equações disponíveis em si e fora de si, mas, ao falar, é falado por um repertório que estabelece suas marcas discursivas. Se digo o meu nome próprio, digo que sou falada por esse nome que escolheram para mim, assim como realizo toda e qualquer operação de convocação de elementos identitários. A disposição de produzir esse modelo de criação já revela o espaço de pertencimento desse sujeito que fala. Não se trata de escrever um poema ou uma narrativa musical que dê conta de um processo de elaboração pessoal, mas trata-se de promover o adensamento de um campo teórico, a partir de uma experiência de efeito significante. Para construí-la, é premente elencar marcadores, a demonstrar os operadores que são usados para descrever as experiências em análise, subsidiando sua legitimidade, na medida em que esta será dada pela forma como o RE é construído e pela presença de elementos teóricos, contextuais, históricos, políticos e críticos, esses atrelados à certeza de que a forma de contar diz sobre quem conta, marca identitária nesse processo de construção narrativa.

As modalidades narrativas, ao particularizar singularidades, prometem um desaguar no campo do comum de algo que possam percorrer e transmitir em inimagináveis concatenações. 
conhecimento assume-se como sintoma em que o sujeito atesta as problemáticas de seu tempo e território, e surge enquanto ato político. Se a modernidade - em concordância com Jean-François Lyotard (2004) - e aquilo que estava correlacionado a ela, condicionando um sujeito de então, fenecem e tombam; a pósmodernidade chega como tensionamento crítico ao modelo positivista e, por sua vez, dissemina e desnorteia horizontes e saberes calculadamente minorizados. Essa instabilidade aufere força ao RE, no âmbito da produção não mais pautada por direcionamentos firmados na constelação moderna de um conhecimento único, mas emparelhada à compreensão pós-moderna, e atesta o dinamismo possuidor de um caráter não centrado no sujeito da razão, agora capaz de suportar paradoxos.

No $R E$, aspectos autoetnográficos podem ser vistos em camadas e posicionamentos diferenciados, associados em perspectiva ao repertório do sujeito pesquisador. Suas técnicas são combinadas a elementos reflexivos, considerados a partir da teoria psicanalítica, antropológica, e alinhados a questões ligadas também a gênero, classe, economia, etc. Portanto, a modalidade que ora apresentamos nos chega como sendo significativa para criar conhecimento no território da saúde e da psicologia. Essa modalidade aposta em um comum em différence no sentido derridiano, naquilo que não é conceito ou palavra, mas uma alternância ou alternativa aberta a fluxos, pois inclui um marcador econômico como aquilo que excede, e, não sendo coisa plena, está veiculada também como espaçamento (Santiago, 1976, p. 23-24). Evidenciar a contribuição singular é devolvê-la ao extrato da consonância em que o eu novamente se torna o outro, não como horizonte que tudo abraça na sua síntese, mas como uma ética de infinitas possibilidades antitéticas.

Isso desdobra-se em um processo formal de construção do RE, no qual o pesquisador/autor só encontra espaço se puder abdicar dos ditames da modernidade e incluir aportes mais complexos, no processo de construção e elaboração de saberes em correspondência com a dimensão pós-moderna, entendida não como um depois da modernidade, mas enquanto perlaboração (durcharbeiten) da mesma (Lyotard, 1987. p. 97). Nessa medida, distancia-se da ideia de ciência moderna, em detrimento da valorização daquilo que Lyotard (2004) chamou de objeto de estudo marginalizado no cotidiano social. Tratase de escrever a experiência singular, tomada como objeto a ser analisado pela perspectiva da heterogeneidade, da diferença. Assim sendo, o registro documental-analítico no RE se coloca como uma ferramenta político/social de compreensão da diversidade própria da ciência contemporânea. 


\section{Percurso Metodológico}

Numa pesquisa de análise documental realizada entre dezembro de 2017 e janeiro de 2018, pelas autoras na Plataforma Sucupira - uma importante ferramenta para coletar informações do Sistema Nacional de Pós-Graduação do Brasil - foi possível avaliar a qualidade de periódicos científicos, alimentados por pesquisadores brasileiros a partir de um sistema de classificação, cujos melhores periódicos são considerados $A 1$, segundo a Coordenação de Aperfeiçoamento de Pessoal de Nível Superior - CAPES. Esse estudo pesquisou os periódicos da área da psicologia, classificados no quadriênio 20132016, como A1 no site da Plataforma Sucupira (https://sucupira.capes.gov.br/sucupira/public/consultas/coleta/veicu loPublicacaoQualis/listaConsultaGeralPeriodicos.jsf).

Um conjunto de 170 periódicos foi investigado e, entre eles, apenas cinco afirmam aceitar o RE como um documento científico, todos periódicos de origem brasileira, vinculados aos mais importantes programas de pós-graduação na psicologia nacional, e situados nas regiões Sudeste e Centro-Oeste. O espaço de laudas, linhas e resumo é em torno de $25 \%$ menor do que o que está garantido aos estudos empíricos e teóricos. Portanto, tal resultado reafirma a limitada força política do RE e a potência da perspectiva empirista cartesiana nos domínios da pesquisa em psicologia.

\section{Resultado e Discussão}

A confecção do documento narrativo não pode estar descrita em um guideline que indica itens e cabem em modelos standards. Tal perspectiva, simultaneamente, liberta e fragiliza a força do RE, em relação ao trabalho empirista cartesiano, recortado por disciplinas, verdades e formas. Faz-se, entretanto, necessário garantir algumas referências metodológicas que admitam a abertura de espaços de circulação de conhecimento mais amplos, e sinalizem caminhos dialógicos com os saberes sobre a ciência e seus sentidos.

Esse artigo circunscreve o RE como uma importante tecnologia de produção de conhecimento científico, especialmente para as ciências que podem e necessitam prescindir da dimensão universalizante e diminuidora dos sujeitos, para priorizar a complexidade humana analisada na perspectiva da pós-modernidade, importante para lidar com dicções e geografias. Assim, elencamos um conjunto de elementos necessários à construção documental do RE, de forma a dar a este uma formatação mais robusta como possibilidade de publicação em bons periódicos, investindo na consolidação de uma política de valorização desse instrumento de produção de conhecimento, especialmente no âmbito da psicologia, ciência e 
profissão que tem, como objeto, complexas dimensões de existência humana.

Com essa proposição dialógica, analisou-se o conjunto das revistas. Este artigo discute e circunscreve o RE como importante tecnologia de produção de conhecimento científico e destaca seis elementos essenciais a sua construção formal:

1. Compreender o RE como uma produção documental afirmada como trabalho de linguagem, de narrativas.

2. A construção documental de um RE implica, a priori, que seu(s) autor(s), ou pelo menos um deles, seja sujeito participante do contexto da vida real em estudo. Diferente de uma Pesquisa-Ação ou de um Estudo de Caso, o RE não é previamente pensado como uma pesquisa, ele é efeito de significação, por isso não pode prescindir da participação ativa do(s) autor(es) do projeto que faz parte do requisito. A significação da experiência, enlaçada à realidade concreta, é identificada no processo ou posteriormente, quando o sujeito - já afetado pelo discurso da ciência - pode localizar a potência de teorização dessa, para o avanço de determinado campo de conhecimento.

3. A experiência vivida deve se apresentar a partir de sua natureza vária. Não se trata de descrever a impossível coisa em si, mas de, a partir da experiência do autor, gerar novas noções teóricas com capacidade de provocar a emergência de outras problematizações e processos; isso inclui uma gama de potentes e necessários elementos, vinculados ao território físico e social, sujeitos, práticas e processos; além da dimensão temporal e relacional, combinando-se a seus efeitos. Trata-se de apresentar, de forma objetiva e rica, o cenário, o texto, os atores e as técnicas utilizadas, em conformidade com o contexto dos envolvidos na experiência, de forma descritiva. Essa modalidade de pesquisa, diferencia-se sobremaneira do Diário de Campo, frequentemente usado nas práticas etnográficas pois, nesta etapa da construção, busca-se um texto explicativointerpretativo que sustente simultaneamente a dimensão abstrata e teórico-metodológica em processo.

4. O manejo do referencial teórico fundamentador da leitura da experiência deve ser apontado para a confecção de novos saberes, a partir de uma escrita política e analítica, revelando o lugar de onde fala o autor. Mais do que ser apresentado como uma redação construída na primeira pessoa do singular, trata-se de oferecer ao leitor referências sobre de que lugar a experiência está sendo falada, singularizada e problematizada, garantindo um diálogo entre os saberes científicos, e muitas vezes não científicos, com os saberes implicados na experiência em estudo.

5. A narrativa de um RE deve ser construída de maneira acessível para todas as pessoas interessadas no tema e não só para pesquisadores, mas as teorias escolhidas devem estar colocadas 
claramente em seus princípios e fundamentos, assim como a problemática que está sendo discutida. Sugere-se que a construção textual possa se aproximar da lógica empirista quando possível, sem, contudo, violar as possibilidades reflexivas e críticas, ou aprisionar as descrições metodológicas que busquem a impecabilidade aparente dos procedimentos visíveis, como afirma Bourdieu (2017). Propõe-se que o texto garanta, em certa medida, as proposições a serem evidenciadas, o referencial teórico, a descrição do contexto, a discussão e as considerações finais.

6. As conclusões devem ser evitadas. O trabalho deve, contudo, considerar os resultados do projeto e das lições aprendidas antes, durante e depois de estruturado um saber sobre a experiência, e desta ter sido discutida como produção singular, diferenciada de outras tantas experiências; mas contradições e lacunas precisam ser apresentadas.

\section{Considerações Finais}

O conjunto dessas análises afiança o Relato de Experiência como uma importante narrativa científica afinada à condição pós-moderna. Trata-se de uma narrativa que, através da linguagem, performatiza a experiência de singularização, atestada em um dinamismo descentrado da razão, e apta a suportar paradoxos.

O RE está compreendido como um trabalho de linguagem, uma construção que não objetiva propor a última palavra, mas que tem caráter de síntese provisória, aberta à análise e à permanente produção de saberes novos e transversais. Configura-se como narrativa que, simultaneamente, circunscreve experiência, lugar de fala e seu tempo histórico, tudo isso articulado a um robusto arcabouço teórico, legitimador da experiência enquanto fenômeno científico.

Nesse contexto, a produção científica autentica-se como complexa, convergindo para a generalidade. Entretanto, não será pela perspectiva da universalidade, mas, pela organização de um território comum, elaborado a partir de diferenças. Em vez de descrição de realidades ou de narrativas sobre a pessoa do autor, anseia por garantir a movimentação expositiva de panoramas críticos, revelando possibilidades de análises referidas sobre lugar e tempo históricos. Serão, consequentemente, análises urdidas em um só depois, après coup, e tramadas enquanto sínteses improváveis, visto que, em cada volta de uma visada que elenca o assunto, o sujeito está sob possibilidade de transformação. Eis um paradoxo necessário, o RE trabalha com um contingente movediço, mas qual seria elemento mais importante do que o constatar não haver verdades absolutas no quesito da cultura? 
Se a cultura é o acordo móbil atravessado por interesses e narrativas constituídos ao longo do tempo, e sendo o sujeito tomado por uma razão que tampouco domina, utilizar o RE como ferramenta metodológica, além de se avizinhar com manejos e direcionamentos estabelecidos nas ciências humanas, exprime, através da própria criação, uma espécie de temperatura de época, ensejando uma aspiração voltada à uma possibilidade de verdade. Não a verdade unificada, estática ou de significância estatística, mas a verdade sintoma, humana e apta a transformações.

\section{Referências}

Bourdieu, P. (2017). Homo Academicus (2a ed.). Florianopolis: UFSC. Deleuze, G. (2002). Espinosa: filosofia prática. São Paulo: Escuta.

Demo, P. (2011). Pesquisa: Princípio científico e educativo (14a ed.). São Paulo: Cortez.

Foucault, M. (2012). As formações discursivas. In A Arqueologia do Saber (8a ed., pp. 39). Rio de Janeiro: Forense Universitária.

Freud, S. (1933/2010). Novas conferências introdutórias à psicanálise. In S Freud, O mal-estar na civilização, novas conferências introdutórias à psicanálise e outros textos 19301936 (P. C. Souza, Trad.). São Paulo: Companhia das Letras.

Gonzáles-Rey, F. L. (2002). Pesquisa qualitativa em psicologia: caminhos e desafios. São Paulo: Pioneira Thomson Learning.

Japiassú, H. (2011). Ciências questões impertinentes. Aparecida, SP: I deias \& Letras.

Lyotard, J. F. (2004). A condição pós-moderna (8a ed., R. C. Barbosa, Trad.). Rio de Janeiro: José Olympio.

Lyotard, J. F. (1987). O Pós-moderno explicado às crianças (T. Coelho, Trad.). Lisboa: Publicações Dom Quixote.

Macedo, R. S. (2016). A pesquisa e o acontecimento: compreender situações, experiências e saberes acontecimentais. Salvador: Edufba.

Minayo, M. C. S. (2004). O desafio do conhecimento: pesquisa qualitativa em saúde (8a ed.). São Paulo: Hucitec.

Pessoa, F. (2011). Antologia poética (9a ed. rev.). Rio de Janeiro: Nova Fronteira.

Roudinesco, E. (1998). Dicionário de psicanálise. Rio de Janeiro: J orge Zahar.

Santiago, S. (Coord.). (1976). Glossário de Derrida. Rio de Janeiro: F. Alves.

Spinoza, B. (2008). Ética (2a ed., T. Tadeu, Trad.). Belo Horizonte.

Stevenson, R. L. (2015). O médico e o monstro: o estranho caso do Dr. Jekyll e Sr. Hyde. São Paulo: Penguin Classics, Companhia das Letras. 
Versignassi, A. (2018). O futuro já aconteceu. E o livre arbítrio não existe. Super Interessante. Recuperado de https: //super. abril.com. br/especiais/o-futuro-ja-aconteceu-e-olivre-arbitrio-nao-existe/

\section{Endereço para correspondência Mônica Ramos Daltro}

Avenida Dom J oão VI, 274, Brotas, CEP 40290-000, Salvador - BA, Brasil Endereço eletrônico: monicadaltro@bahiana.edu.br

\section{Anna Amélia de Faria}

Avenida Dom J oão VI, 274, Brotas, CEP 40290-000, Salvador - BA, Brasil

Endereço eletrônico: annafaria@bahiana.edu.br

Recebido em: 14/10/2018

Reformulado em: 15/04/2019

Aceito em: $24 / 04 / 2019$

\section{Notas}

* Professora Titular do curso de Psicologia, do Mestrado em Psicologia e Intervenções em Saúde e do Doutorado em Medicina e Saúde Humana da Escola Bahiana de Medicina e Saúde Pública.

** Professora Adjunta do curso de Psicologia do Mestrado em Psicologia e Intervenções em Saúde a Escola Bahiana de Medicina e Saúde Pública.

Este artigo de revista Estudos e Pesquisas em Psicologia é licenciado sob uma Licença Creative Commons Atribuição-Não Comercial 3.0 Não Adaptada. 